\title{
Study on Design Aesthetic Education in Universities in China
}

\author{
Lin Yang ${ }^{1, *}$ Heng Cui ${ }^{1}$
}

\author{
${ }^{1}$ School of Art and Design, Nanjing Institute of Technology, Nanjing, Jiangsu 211167, China \\ *Corresponding author. Email: yanglinwhu@163.com
}

\begin{abstract}
The paper uses the comparative analysis method to research Design Aesthetic Education in universities in China in order to construct the new system of aesthetic education with the combination of design aesthetics and traditional art courses. What has been disclosed is that Design Aesthetic Education, compared with Art Education, would aim at the cultivating of aesthetic judgements and understanding of designs that exist ubiquitously in everyday life, which could promote the transformation of the contemporary aesthetic education in Chinese universities that lacks of the intimate connection with students' daily life. It has been explained that students have the spontaneous interests in design, and that could be guided to turn into conscious aesthetic judgements of design and the emotional identification of certain design culture. Also the objectives, the curriculum system and the possible teaching approach have been discussed in this paper.
\end{abstract}

Keywords: Design Aesthetic Education, Art Education, objectives, curriculum, Experiential Education

Method

\section{INTRODUCTION}

Aesthetic education in Chinese universities has been practiced for almost one hundred years, since Cai Yuanpei proposed the concept of aesthetic education and began to set up the curriculums in Peking University in 1920s. However, how should the general aesthetic education in universities be promoted? It has not been researched academically until 1980s. Zhang Xinjian [1] started the research in 1986, who explained the importance and functions of aesthetic education in Higher Institutes. Aesthetic Education in Universities [2], the first publication on this thesis in 1995 was the prominent achievement in the last decade in 20th century. Since then, more and more researchers have paid attention to the theory and practice against the background of the rapid development of Chinese universities. In the past twenty years, the researches as followed have been put forward: the analysis of boundaries between aesthetic education and art education [3], the discussion of the proper curriculum system and the final purpose of aesthetic education [4], the reflection on the history of Chinese aesthetic education in universities based on the transforming of the professional art education to the general selective art courses [5], the exploring of possible mediations of

*Fund: Supported by the Innovation Fund of Nanjing Institute of Technology, Project Name: Research on the Production Mode of Industry design in China influenced by the Culture of Craftsmanship; Project number: CKJB201707. aesthetic teaching and learning methods based on the experiences [6], and the criticizing on the single knowledge-learning method of aesthetic education in universities [7]. Those researches have gradually constructed the basic concepts and thoughts of aesthetic education in Chinese Higher Education Institutes, and have been practiced in a wide range.

The new problem has arisen along with the extension of aesthetic objects in life. Should Art Education still be the only main approach of general aesthetic education in universities? Dissenting voices have already appeared. Xie Yujie and Tan Xudong[8] proposed that art courses as the unique approach have difficulties in promoting students' aesthetic ability in everyday life, and aesthetic education in universities of science and technology could be closely referred to the different kinds of inter-disciplinary education. Yi Jianfang [9] who firstly put forward the concept of Design Aesthetic Education, has done the comparative analysis of art Aesthetic Education and it, and called for the reform of Aesthetic Education in China with the integrating of Design Aesthetics. Those researches have turned out that it is a new meaningful thesis to focus on the possibility and necessity of Design Aesthetics as the new content of general aesthetic education in universities. But what is Design Aesthetic Education? Why is it necessary to develop Design Aesthetic Education in universities? How should it be promoted? These are the three questions that the paper tried to make clear. 


\section{DESIGN AESTHETIC EDUCATION IN UNIVERSITIES}

Design Aesthetic Education shares the same purpose with general Aesthetic Education, which aims at enriching and developing students' individual sense perception and understanding of beauty and cultivating students' ability of aesthetic sentiments and judgments. In universities, Aesthetic Education normally has been provided by professional teachers with the method to implement the knowledge-learning study of Aesthetics and art theory, and the discussion-based experiential study of various kinds of specific art works, such as film, music, paintings, opera, etc. So far the knowledge of design aesthetics has seldom been included in the curriculum of university.

In order to explain the concept of Design Aesthetic Education, it is absolutely indispensable to do the comparative analysis between Art Education and it, because Art Education has been the main form of general Aesthetic Education in universities for many years in China.

There are four factors taken into account in the comparative analysis between Design Aesthetic Education and Art Education:

- Knowledge content: what students would obtain in the related curriculum in universities

- Situational teaching method: how the good aesthetic taste would be cultivated

- Integration with other discipline cultures: how Aesthetic Education would be integrated with other disciplines.

- Application of knowledge: how students would apply the knowledge obtained in courses

TABLE I. The COMPARATIVE ANALYSIS OF DESIGN AESTHETIC EDUCATION AND ART EdUCATION

\begin{tabular}{|l|l|l|}
\hline & \multicolumn{1}{|c|}{ Design Aesthetic Education } & \multicolumn{1}{c|}{ Art Education } \\
\hline Knowledge content & $\begin{array}{l}\text { Aesthetic knowledge of Design (including that of } \\
\text { products, environment, informational mediations, } \\
\text { architectures, etc.) }\end{array}$ & $\begin{array}{l}\text { Aesthetic Knowledge of Arts(including that } \\
\text { of painting, sculpture, music, dance, } \\
\text { literature, film, opera, etc.) }\end{array}$ \\
\hline $\begin{array}{l}\text { Situational teaching } \\
\text { method }\end{array}$ & $\begin{array}{l}\text { Intellectual and emotional teaching and learning with } \\
\text { the imagination of being a user of certain products } \\
\text { integrated with form and function }\end{array}$ & $\begin{array}{l}\text { Intellectual and emotional teaching and } \\
\text { learning with super-utilitarian aesthetic } \\
\text { appreciation }\end{array}$ \\
\hline $\begin{array}{l}\text { Integration with other } \\
\text { discipline cultures }\end{array}$ & $\begin{array}{l}\text { Flexibility of integration based on the wide-ranged } \\
\text { concepts of products in design }\end{array}$ & Relatively inflexible \\
\hline $\begin{array}{l}\text { Application } \\
\text { knowledge }\end{array}$ & $\begin{array}{l}\text { Connected more closely with everyday life because of } \\
\text { the ubiquitous designs }\end{array}$ & $\begin{array}{l}\text { Depending on exhibitions or programs } \\
\text { provided by cultural organizations }\end{array}$ \\
\hline
\end{tabular}

As "Table I" has shown, Design Aesthetic Education has totally different knowledge content compared with Art Education, because the division between design and art is obvious nowadays. Function is the clear dividing line between designed objects and art works, which determines the situational teaching method that is commonly applied in aesthetic education would present itself as totally different forms. In Design Aesthetic Education, students would be guided into an imagined sensuous experience context as a user, whereas in Art Education as an audience with superutilitarian aesthetic attitude. The super-utilitarian characteristic of art appreciation also decides that it is relatively inflexible for art education to integrate with other disciplinary culture; whereas Design Aesthetic Education has more flexibility since designed products is a wide-ranged concept. Thus Design Aesthetic Education in connected more closely with everyday life.

\section{REASONS WHY DESIGN AESTHETIC EDUCATION SHOULD BE DEVELOPED IN CHINESE UNIVERSITIES}

Design Aesthetic Education is a new reforming orientation. Whether it would be promoted or not depends on the needs and interests of students in universities of science and technology. In fact, it is the achievement of Art Education in Chinese universities which has changed students' attitudes for art and behaviors of visiting art galleries that have also inspired students' interests for design aesthetics.

Let's take the results of Art Education into account firstly. Art Education is the main component of the general aesthetic education in Chinese universities, whether they are the multi-disciplinary comprehensive university or those of science and technology. Its development has been guaranteed by National Department of Education. According to Guidelines of General Art courses in National Higher Educational Institutes in 2006, the policy formulated by Ministry Education, Chinese universities must set up general Art courses, as the "Fig. 1" has shown. 

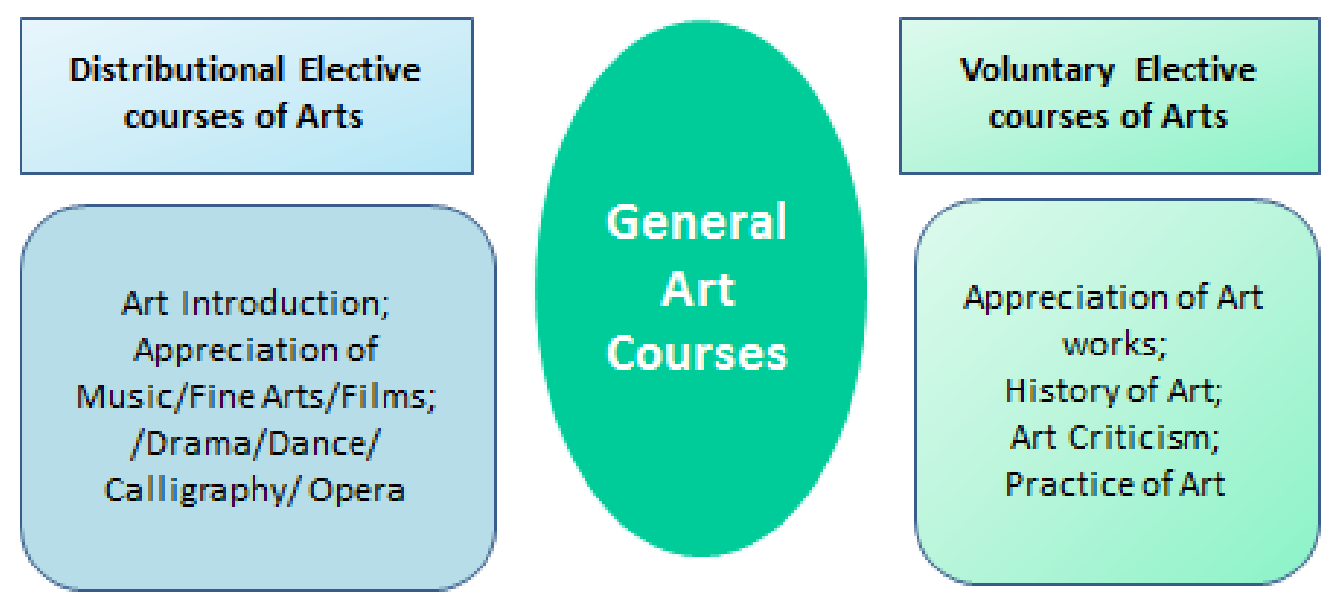

Fig. 1. General Art Courses in Chinese universities.

Achievements in Art Education in universities could be found in the reference of the data of students who would like to go to art galleries in their leisure time. According to the report in Chinese Culture Daily, there was $10 \%$ students in universities have been to art galleries in 2008 [10]. While in 2018, according to statistically analysis by Li Ruojin [11], more and more students have been to art galleries and other art exhibitions: there are only $9.52 \%$ students in universities in Shanghai who have never been to any art gallery or exhibition, $14.42 \%$ in Shijiazhuang and $23.24 \%$ in Nanning. Li Ruojin also provided the data of types of exhibitions that students in universities would like to visit in three cities [12]. It could be concluded in "Fig. 2".

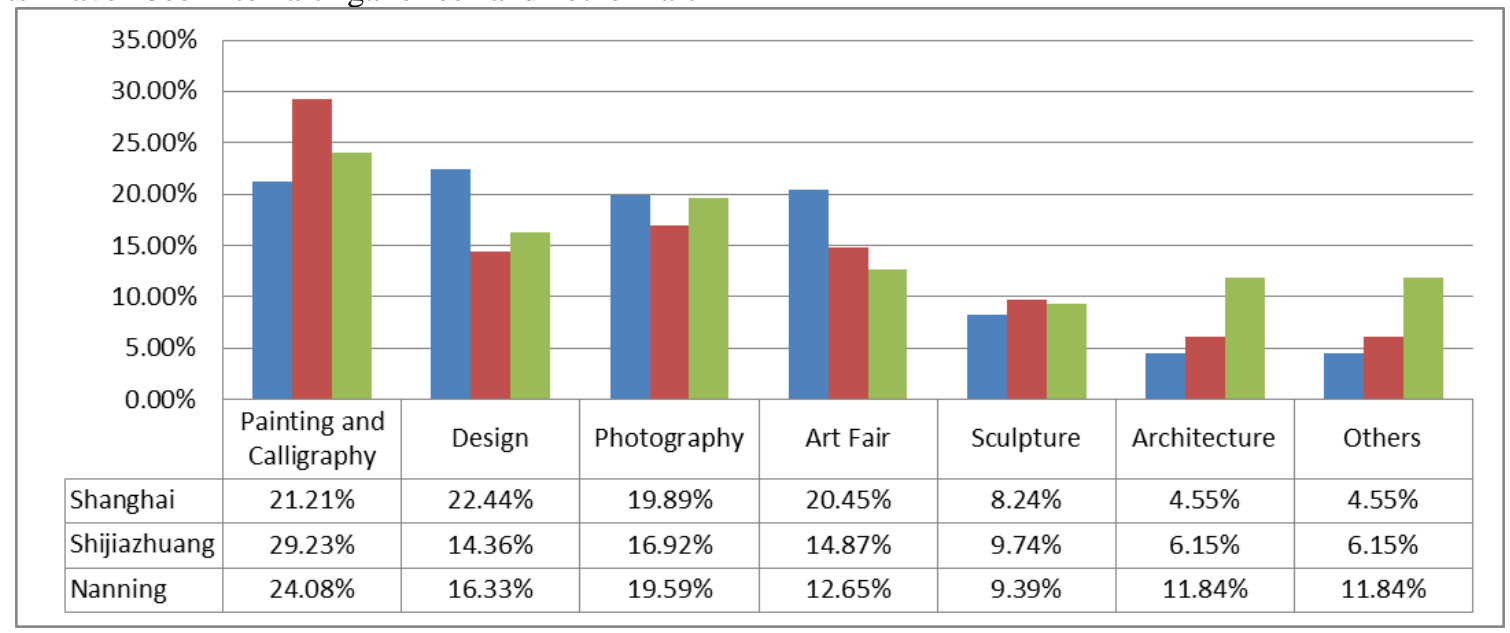

Fig. 2. Types of exhibitions students in universities would like to visit in three cities in 2018.

Design exhibitions, as "Fig. 2" has shown, have been the new phenomena that have appeared in the leisure life of students in Chinese universities. Especially in Shanghai, students showed the greatest interests to design exhibitions than others, which was 22.44\%; whereas the percent of visiting to exhibitions of painting and calligraphy, sculpture and art fair were respectively $21.21 \%, 8.24 \%$ and $20.45 \%$. Even in Shijiazhuang and Nanjing, students in university have shown the obvious interests for design exhibitions.
The reasons why students in universities have shown more interests in design could be concluded in four points:

- Design is ubiquitous in everyday life;

- Design has integrated with new technologies more closely than Art;

- Design is now changing the life-style which is more readily accepted by young people;

- Design, with its creative concepts, could inspire the imagination of the future. 
As far as the above four reasons were concerned, the importance of promoting Design Education in Chinese universities have been more evident. Students in Chinese universities are young people, who are sensitive to the emergency of new things, especially those designed objects or concepts provided by the advanced science and technology. The interests of students for design are spontaneous, which should be guided by Design Aesthetic Education that could help students form their conscious aesthetic judgements and understanding.

\section{WAYS TO PROMOTE DESIGN AESTHETIC EDUCATION IN CHINESE UNIVERSITIES}

\section{A. Objectives of Design Aesthetic Education}

Design Aesthetic Education requires some basic specific knowledge of design aesthetics to recognize, describe and understand the beauty of designs in everyday life. Design aesthetics also is the new phenomena in aesthetics, which expanded the research range of traditional aesthetics that normally focused on art and ignored daily necessities. The super-utilitarian nature of beauty, as the core concept of European traditional Aesthetics has been criticized in recent years, especially in educational perspective. As Liu Yuedi has said, aesthetic education in China should orient to everyday life, and Art would not be the unique center of aesthetic education; what is the most important in future is to cultivate the aesthetic judgement and understanding of beauty existing in daily life, not only in art in museums and galleries. [13]

The objectives of Design Aesthetic Education should include three aspects, as "Fig. 3" has shown.

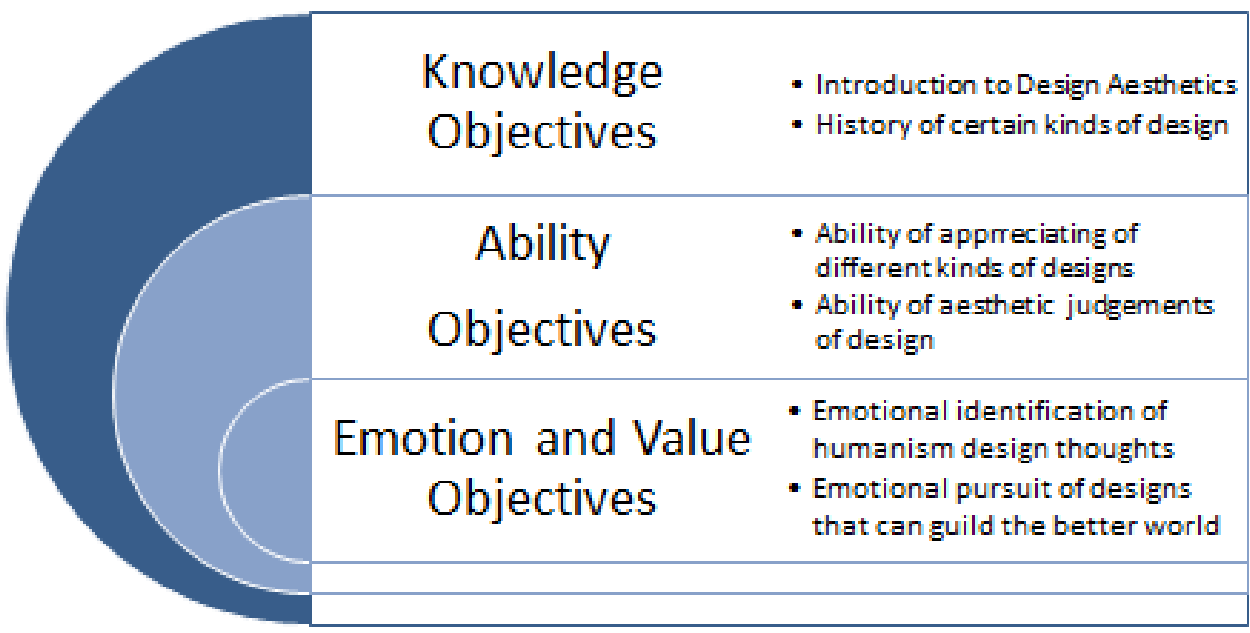

Fig. 3. Objectives of Design Aesthetic Education.

In the system planning of objectives of Design Aesthetic Education, as "Fig. 3" has shown, knowledge objectives is the foundation, which help the students in universities to set up the basic recognition concepts about Design Aesthetics and the history of industry design. Ability objectives is the direction which guide students to apply the knowledge, since designs not like arts, could be felt and judged aesthetically almost in every sphere of daily life. Emotion and value objects have been set as the ideal of Design Aesthetic Education, and they could ensure the design aesthetic judgements and understanding transforming into a kind of emotional identification for the national culture, the universal values about humanism in design.

\section{B. Curriculum planning of Design Aesthetic Education}

Like Art Education in universities, Design Aesthetic Education would be a branch of general selective courses provided to students in universities. As "Fig. 4" has shown, it could be one part parallel to contemporary art courses in universities. Also like art courses, these courses as followed could be provided: the introduction to design culture and its aesthetics, the history of product design / industry design / visual design / environment design. 


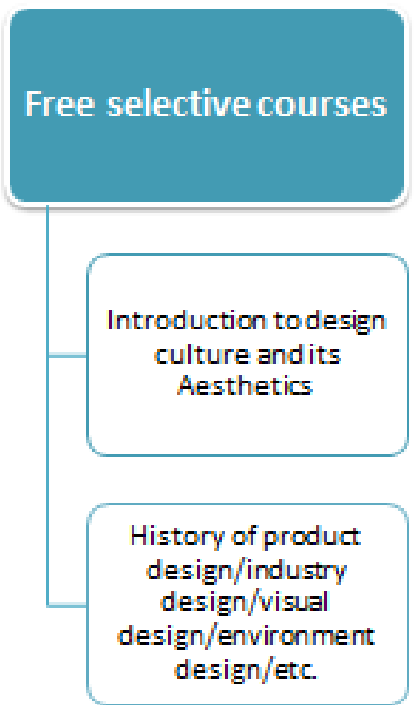

Fig. 4. Curriculum planning of Design Aesthetic Education.

However, there is one kind of specific courses that Design Aesthetic Education could exploit. That is, the inter-disciplinary aesthetic courses of designs, which could be the characteristic selective courses in universities. Design itself is an inter-disciplinary phenomenon, which integrate the laws of forms in art with the skills in other disciplines, such as material, engineering, information science, intelligent technology, etc. How could the aesthetic experience be integrated into products provided by the application of

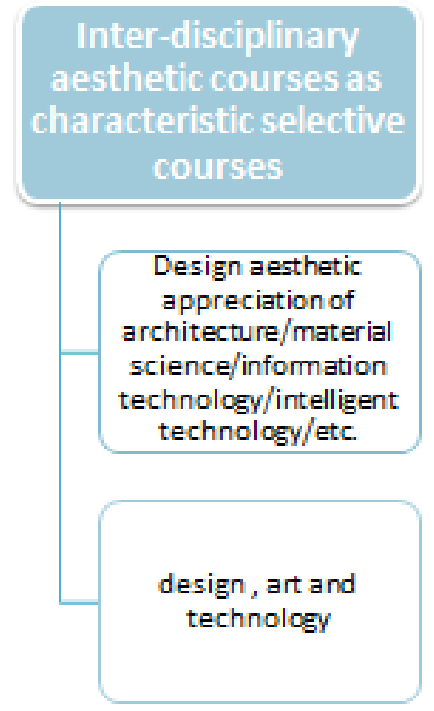

specific technology? Creative thinking method could be guided in those kind of courses.

\section{Experiential Education of Design as the supplement} of intellectual learning

Experiential education of design should make full use of the campus, products and digital media of universities. What kind of designed objects could students in universities find out in their daily life? It could be seen in "Fig. 5".

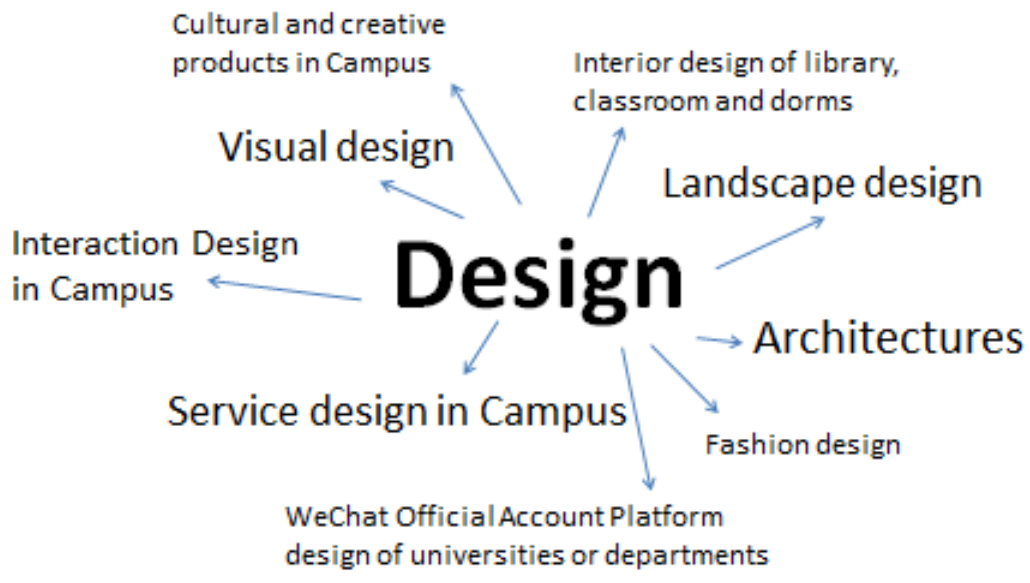

Fig. 5. Designed in the campus of universities.

As "Fig. 5" has shown, design could be found everywhere in the campus of universities. It includes two basic kinds: the material and immaterial design.

- Material design: Architectures; Landscape design; graphic design(logos, posters, advertisement in campus); Cultural and creative products in Campus; Interior design(of library, classrooms and dorms); Fashion design; etc.

- Immaterial design: Service design in Campus; Interaction Design in Campus; WeChat Official Account Platform design of universities or departments; Website design; etc. 
Students spontaneously have encountered all kinds of designed objects; no matter they are material or immaterial. However, it's not easy for them to obtain aesthetic judgements and understandings of design by themselves without the teacher's guide in direct experience. In fact, there are a lot of universities especially those with more than a century history, which has classical architectures, landscape design and other special design. It would be meaningful for students to understand the history of design culture of their universities. Moreover, students need to be encouraged to attend the concept design activities of new things in the campus, especially those immaterial designs supported by new information technologies.

Experiential education thus could be programmed with the emotional and intimate connection in the campus of universities. It should be promoted following the laws of aesthetic psychology. As "Fig. 6" has shown, student's aesthetic psychology is a gradually promoting process from the spontaneous sense of designs to the aesthetic experience and finally to the aesthetic understanding.

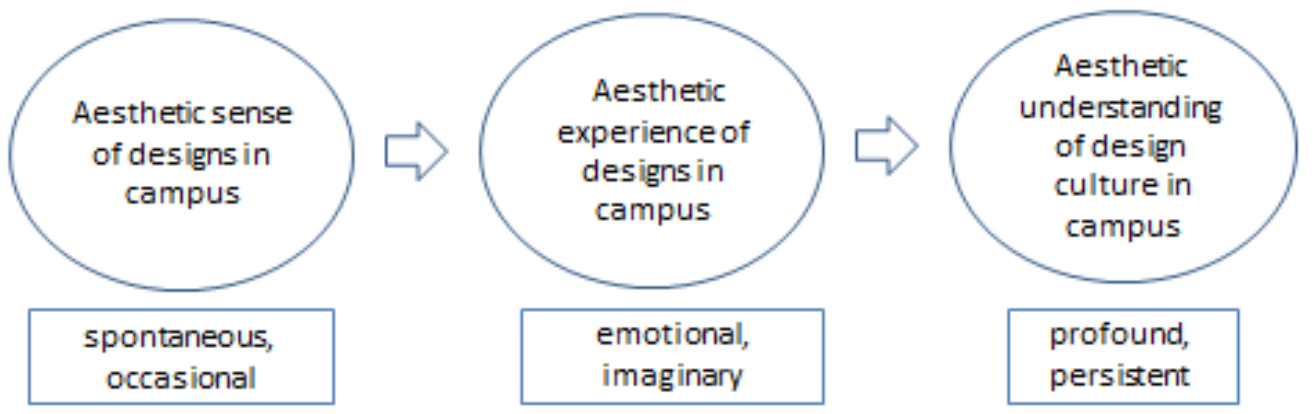

Fig. 6. Transforming of students' aesthetic psychology of design in universities.

Therefore, different educational approaches should be planned correspondingly, which aim at the cultivating of the aesthetic judgement of design. Those include: the detailed introduction of the designs in the campus which help students to understand how the designs have been creatively appeared from the ideal to the final forms; the campus cultural activities which encouraged students to participate the concept design of the new campus; the experience program of the design culture in universities. These measures could be regarded as the experimental approaches to promote the experiential education of design aesthetics.

\section{CONCLUSION}

This paper focused on Design Aesthetic Education as an innovation of traditional mode of aesthetic education in Chinese universities which have developed art courses as the center. Design has more intimate connection with everyday life of students, could be experienced at any place in daily activities and be closely related with the update new technologies. That is why it is important to make full use of the spontaneous interests of students in university to promote Design Aesthetic Education which aims at the cultivation of aesthetic judgements and understandings of design and its culture. The possible curriculum system of Design Aesthetic Education and the Experiential Education Method advised in the paper will be dependent on the teaching groups, also on the achievements of researches of Design Aesthetics in the future.

\section{References}

[1] Zhang Xinjian. On Aesthetic Education in Higher Institutes[J]. Journal of Anhui University, 1986(1): 53-58.

[2] Zhao Lingli, Zhang Xinjian. Aesthetic Education in Universities[M]. Publication of Southwest University, 1995: 3-5

[3] $\mathrm{Xu}$ Yanxia. On the Relationship between the Aesthetic and Art Education: Several Analyses on Aesthetic Education in Universities[J]. Northern Music, 2017(19): 149-150.

[4] Ran Xianghua. The Design and Practice of the aesthetic curriculums in Universities[J]. Heilongjiang Researches on Higher Education, 2008(9): 177-179.

[5] Peng Jixiang. On Leap - forward Development of Aesthetic Education and Art Education in China in the New Era[J]. Journal of Aesthetic Education, 2019(5): 11-16.

[6] Zhou Xian. Tension of Knowledge and Action, Intermediality and Empathic Experience: Three Issues of Current Aesthetic Education in Universities[J]. Journal of Aesthetic Education, 2019(5): 1-10.

[7] Wang Yi, Fu Xiaowei. Causes of the Weakness of Aesthetic Education in Chinese Higher Education- Philosophical Thoughts on Aesthetic Education/Aesthetics[J]. Journal of Aesthetic Education, 2017(6): 28-34.

[8] Xie Yujie, Tan Xudong. The Approach and Meaning of Aesthetic Education in Universities of Science of Technology[J]. Higher Education Exploration, 2010(4): 133 134.

[9] Yi Jianfang. On the Temporality of Public Aesthetic Education: An Comparative Analysis of Art Aesthetic Education and Design Aesthetic Education[J]. Arts \& Design, 2010(5): 90-91.

[10] Fan Dian. Art Galleries Should Undertake the Responsibility of Public Aesthetic Education[N]. Chinese Culture Daily, 2008-312: 5 .

[11] Li Ruojin. The Study on the Art Exhibition Visiting Behaviors and Influencing Factors of Contemporary College Students 
Based on Regional Differences [D]. Shanghai Jiao Tong University, 2018: 30-31.

[12] Li Ruojin. The Study on the Art Exhibition Visiting Behaviors and Influencing Factors of Contemporary College Students Based on Regional Differences [D]. Shanghai Jiao Tong University, 2018: 29.

[13] Liu Yuedi. "Aesthetic Education in Life" That Aims for Aesthetics of Life: How to Construct a New Aesthetic Education in 21st century China [J]. Journal of Aesthetic Education, 2012(6): 24-30. 